\title{
Mechanical properties of modified HDPE by ionizing radiation after temperature load under and above the pure HDPE melting temperature
}

\author{
Pavel Stoklasek, Ales Mizera ${ }^{a}$, Miroslav Manas, David Manas, Martin Bednarik and Vaclav Janostik \\ Tomas Bata University in Zlin, nam. T.G. Masaryka 5555, 76001 Zlin, Czech Republic
}

\begin{abstract}
Radiation processing of polymers is a well-established and economical commercial method of precisely modifying the properties of polymers, especially mechanical properties. The mechanical properties of modified HDPE samples by beta rays were measured at the ambient temperature and after temperature load under and above the pure HDPE melting temperature. The tested samples showed significant changes of mechanical behaviour before and after temperature load. From this point of view, new applications could also be seen in areas with service temperatures higher than their former melting point.
\end{abstract}

Keywords: tensile strength, hardness, radiation cross-linking, high density polyethylene, temperature load.

\section{Introduction}

Polymers belong to constructive materials which find use at the most industry branches. The advantage is a low weight together with the excellent mechanical properties, very good chemical resistance and other properties, which assign them for various applications. Disadvantage is mainly low temperature stability which significantly reduces usage of these polymers.

Radiation processing of polymers involves treatment of polymer materials with ionizing radiation to modify their physical and chemical properties to make property improvement. Therefore, the use of ionising radiation has found a very wide range of applications in medicine, agriculture and industry. Many scientists have examined the issues of polymer radiation cross-linking. They discovered that some of polymer materials exposed to ionizing radiation tend to either improve or worsen their mechanical properties. It depends on their chemical structure if polymers cross-link or degrade predominantly [1 - 9].

Radiation cross-linking usually improves thermo-mechanical and mechanical properties. Effect of radiation cross-linking significantly improves mechanical behavior after temperature load. Because of that, materials which belong to group of standard polymers can be used in applications, which would be in term of mechanical behaviour intended only to constructive thermoplastic polymers. Hence more polymer materials and a wider range of irradiation doses will be investigated to confirm or deny these findings.

\footnotetext{
${ }^{a}$ Corresponding author: mizera@fai.utb.cz
} 


\section{Experimental}

\subsection{Material}

As the basic polymer material was used high density polyethylene (DOW HDPE 25055E). An ARBURG Allrounder 420C Advance Injection molding machine was used for sample preparation, with the processing conditional to comply with the HDPE producer's recommendations.

\subsection{Irradiation of samples}

Irradiation of tested LDPE polymer was performed with the kind help of BGS Germany, in the BGS Wiehl plant using accelerated electrons with a dosage range of 0 to $198 \mathrm{kGy}$.

\subsection{Sample temperature load}

Non-modificated and modificated samples of HDPE were exposed temperature $110{ }^{\circ} \mathrm{C}$ and samples with the dosage of irradiation higher than $99 \mathrm{kGy}$ were exposed temperature $180^{\circ} \mathrm{C}$ and $220{ }^{\circ} \mathrm{C}$ during 15 minutes, then all these samples were cooled spontaneously to ambient temperature.

\subsection{Used methods for the testing}

The tensile behaviour of temperature non-loaded and loaded samples of LDPE were measured at the ambient. Tensile test was carried out on tensile test machine ZWICK 1456 for HDPE according to standard CSN EN ISO 527-1, 527-2 with used rate $50 \mathrm{~mm} / \mathrm{min}$. Test data was processed by Test Expert Standard software and E-modulus [MPa], tensile strength [MPa] and elongation at break [\%] were determined. Hardness was measured using a HPE - D Berreiss hardness tester type, and the Shore D Method. The shape and dimensions of the testing samples were in accord with the CSN 621431 standard.

\section{Results and discussion}

The tensile behaviour and hardness of high density polyethylene, before and after irradiation, was studied. For easier of evaluation of the measured data, and the comparison of the irradiated polymer with a non-irradiated one, the changes of measured were used on some graphs. The property of the non-irradiated polymer had the value of $100 \%$, while others were expressed in $\%$ as the ratio of measured property of irradiated polymers to the same property of non-irradiated polymer.

\subsection{HDPE tensile test}

Irradiation affects the tensile behaviour of the HDPE was studied at ambient temperature and after temperature load. After performing the tensile test at ambient temperature three observed parameters (E-modulus, tensile strength, and elongation at break) were compared. The value of non-irradiated sample E-modulus was measured $1247 \mathrm{MPa}$ at $23^{\circ} \mathrm{C}$. As can be seen from figure 1, there was a slight growth of the E-modulus with dose of irradiation $33 \mathrm{kGy}$ about 3\%. However, E-modulus with the increasing dose after temperature load decreases between 2 and $8 \%$ in comparison of non-irradiated sample before temperature load. 


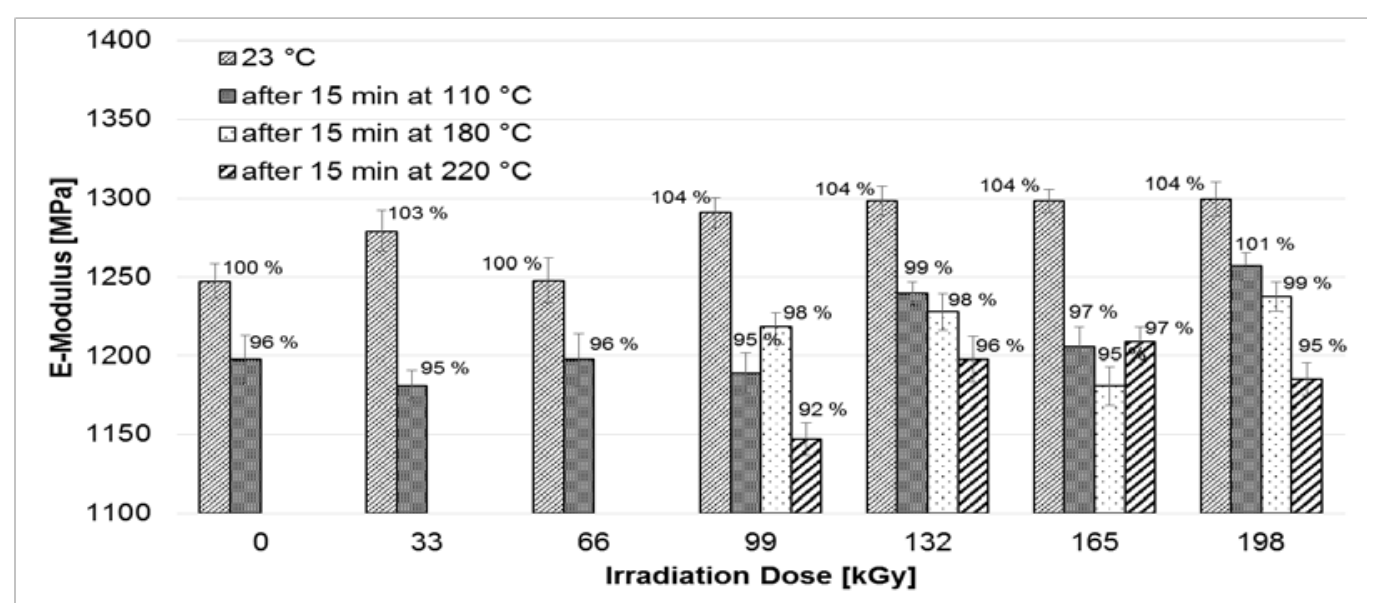

Figure 1. HDPE E-modulus.

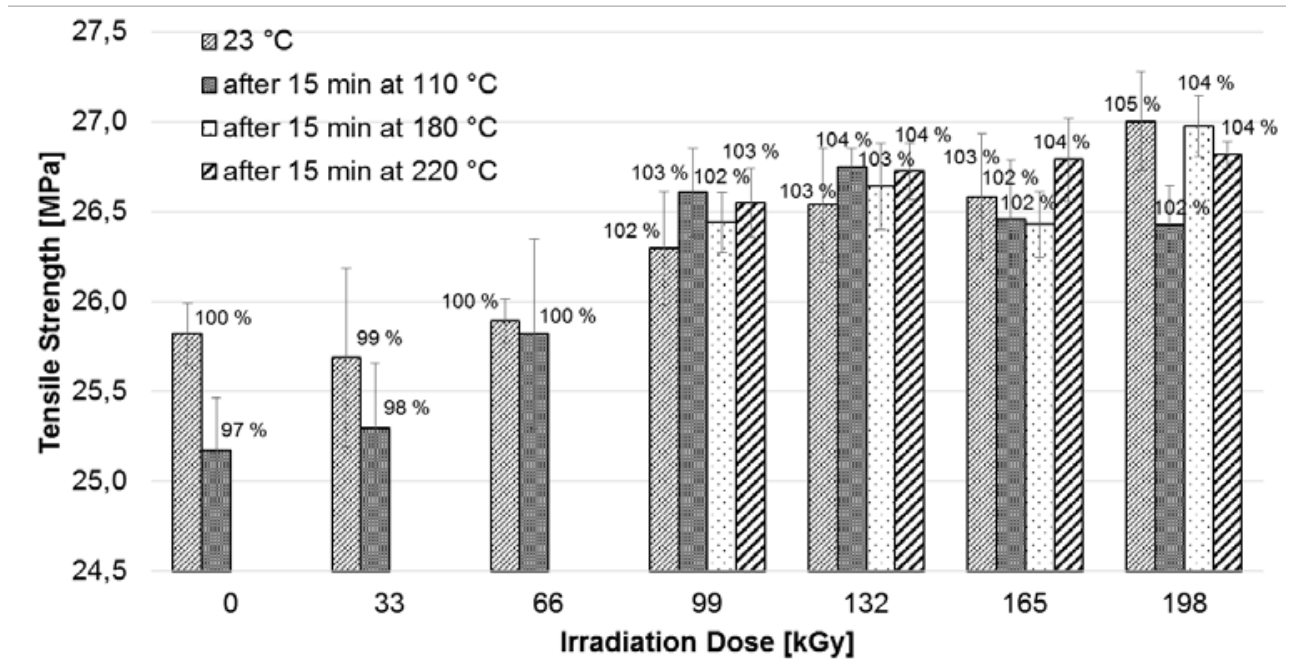

Figure 2. HDPE tensile strength.

The value of non-irradiated sample tensile strength was measured $25.8 \mathrm{MPa}$ at $23{ }^{\circ} \mathrm{C}$. As can be seen from figure 2 , there was not a significant growth of the tensile strength with increasing doses of irradiation and after temperature load. The value of non-irradiated sample elongation at break was measured $201 \%$ at $23{ }^{\circ} \mathrm{C}$. As can be seen from figure 3, there was a significant decrease of the elongation at break with increasing doses of irradiation. The elongation at break rises about $15 \%$ after irradiation with a dosage of $33 \mathrm{kGy}$ and temperature load at $110^{\circ} \mathrm{C}$ in comparison with non-irradiated HDPE. However, the elongation at break after temperature load at $220{ }^{\circ} \mathrm{C}$ with a dosage of $198 \mathrm{kGy}$ decreases about $50 \%$ in comparison with non-irradiated HDPE before temperature load. 


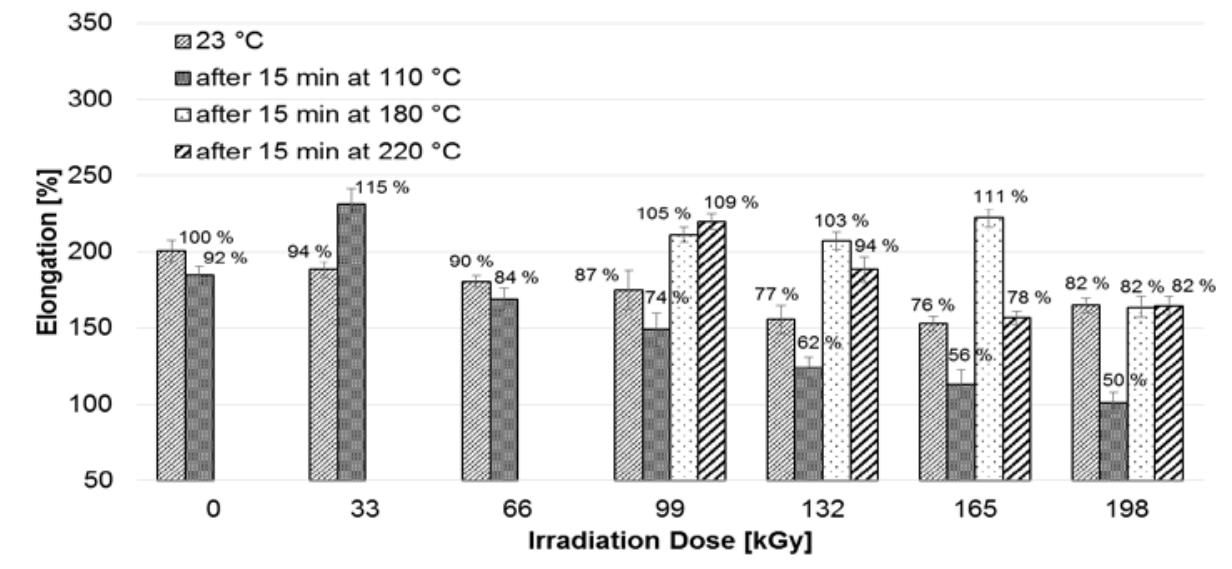

Figure 3. HDPE elongation.

\subsection{HDPE hardness test}

Irradiation affects the hardness of the HDPE was studied at ambient temperature and after temperature load. After performing the hardness test at ambient temperature three observed parameters (hardness according to Shore D) were compared. No significant changes of hardness were found after the irradiation on the HDPE sample. A maximum increase of hardness (i.e. about 8\%) was measured after the irradiation dosage of $99 \mathrm{kGy}$. Higher doses of irradiation had no significant effect on the Shore D Hardness (Fig. 4). Nevertheless, the hardness after temperature load decreases about $10 \%$ in comparison without temperature load HDPE.

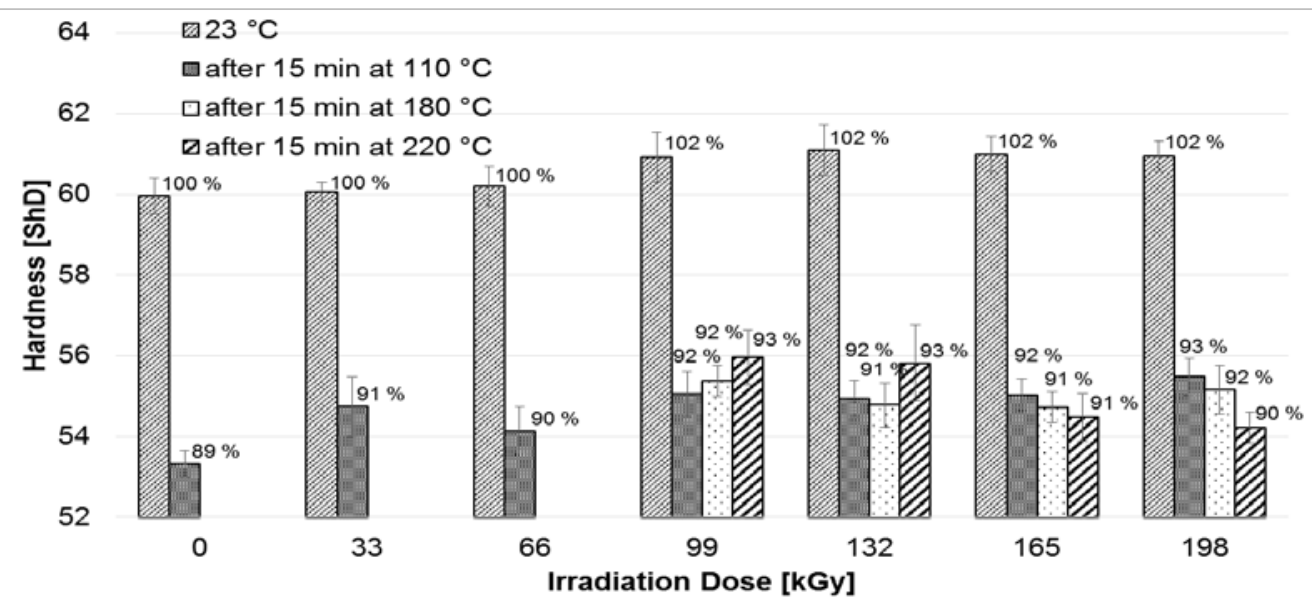

Figure 4. HDPE hardness.

\section{Conclusions}

Experiments done in this project showed that irradiation cross-linking markedly affected the mechanical properties of the HDPE studied. The higher the irradiation dosage, the better the mechanical behaviour of studied polymers is at the higher temperature. As can be seen from the tests results, the irradiation cross-linking slightly improves the HDPE tensile behaviour and hardness. 
Irradiation improves the thermal properties of polymer. Tested polymer (HDPE) shows better temperature stability after irradiation. Because of melting of irradiated samples up to $99 \mathrm{kGy}$ measurement could not have been done. Irradiation significantly extends the application area of polymers. The service temperature can be higher than the melting point of not irradiated polymers.

The results of the measurements of HDPE after irradiation showed significant changes of its mechanical properties. The E-modulus decreases only about $3 \%$, after irradiation with a dosage of $165 \mathrm{kGy}$ after temperature load at $220{ }^{\circ} \mathrm{C}$ in comparison of non-load sample. The tensile strength is almost constant before and after temperature load. The elongation at break rises by $11 \%$, after irradiation with a dosage of $198 \mathrm{kGy}$ and after temperature load at $180{ }^{\circ} \mathrm{C}$ in comparison of non-load sample. The hardness is not changed after irradiation and temperature load. However, a very important point is the improvement of the HDPE specimen temperature stability, after irradiation.

\section{Acknowledgments}

This paper is supported by the internal grant of TBU in Zlin No. IGA/FT/2016/010 funded from the resources of specific university research and by the Ministry of Education, Youth and Sports of the Czech Republic within the National Sustainability Programme project No.LO1303 (MSMT7778/2014) and also by the European Regional Development Fund under the project CEBIA-Tech No.

CZ.1.05/2.1.00/03.0089.

\section{References}

1. J.G. Drobny, Radiation Technology for Polymers, CRC Press, 2010.

2. K. Makuuchi and S. Cheng, Radiation Processing of Polymer Materials and Its Industrial Applications, John Wiley \& Sons, 2012.

3. D.W. Clegg and A.A. Collyer, Irradiation Effect on Polymers, Elsevier Science Publications, 1991.

4. R.L. Clough and S.W. Shalaby, Irradiation of Polymers: Fundamentals and Technological Applications, American Chemical Society, 1996.

5. S. M. Tamboli et al., Indian J. Chem. Tech. 11 (2004) 853-864.

6. H. A. Khonakdar et al., Radiat. Phys. Chem. 75 (2006) 78-86.

7. S. Dadbin et al., J. Appl. Polym. Sci. 86 (2002) 1959-1969.

8. S. P. Hlangothi et al., Polym. Degrad. Stabil. 79 (2003) 53-59.

9. I. Krupa et al., Polym. Degrad. Stabil. 73 (2001) 157-161. 